\title{
Patients in Wales face 90-mile round trips to see dentists
}

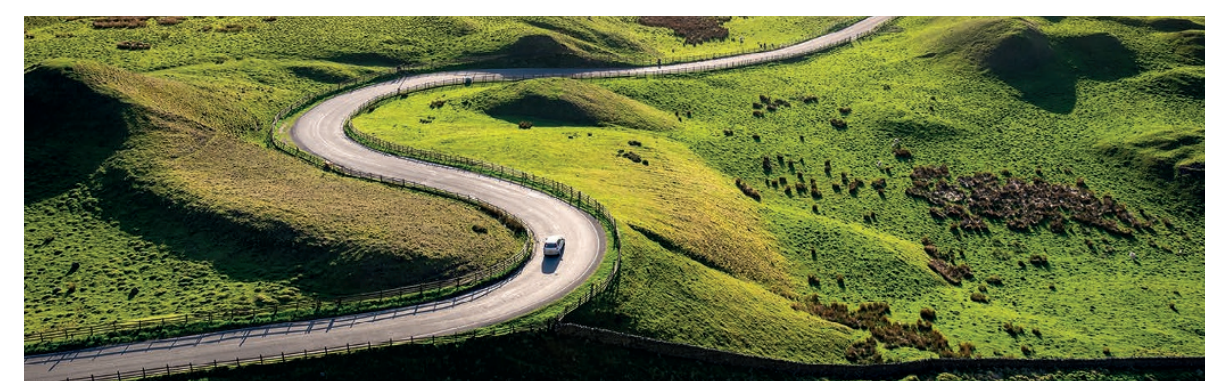

Some patients in Wales are being forced to travel up to 90 miles to see a dentist for NHS treatment because funding for dental services has been cut significantly in recent years, dental leaders have warned politicians.

Access problems were highlighted by the BDA during an evidence session held on 27 September 2018 of the Welsh Assembly's Health, Social Care and Sport Committee for its inquiry into the future of NHS dental care.

The BDA's witnesses told the Welsh Assembly Members that patients across Wales faced a 'postcode lottery' of care because the number of people being treated by dentists on the NHS was being capped.

They cited a recent analysis of data ${ }^{1}$ from the official NHS Direct service in Wales that showed new patients were making long journeys to see an NHS dentist, with residents in Aberystwyth, for example, facing a 90-mile round trip. New patients in Newtown faced 80-mile journeys, while even those in the Welsh capital Cardiff were looking at an almost 30-mile journey.

The BDA told politicians that it had carried out an analysis of official data on NHS budget allocated to general dentistry in Wales taken away from direct patient care in 2014-17. There had been a reduction of $£ 20.6$ million through processes of clawback, handback and contract reductions in this three-year period.

Further BDA analysis from last year had shown that only $15 \%$ of NHS practices were taking new adult NHS patients, with just 28\% accepting new child patients.

BDA Wales supported initiatives such as Designed to Smile, ${ }^{2}$ which had narrowed deep health inequalities among young children, but it criticised the Welsh Government for failing to apply these effective preventive principles to wider strategy and reform of the 'failed' NHS system.

Tom Bysouth, Chair of the BDA's Welsh
General Dental Practice Committee, said: 'The Welsh Government talks about prevention, inequalities and sustainability. But we require deeds not words to guarantee the future of this service and end the postcode lottery of care.

'It's utterly perverse that $£ 20$ million has been lost from local services, while some patients are travelling 90 miles to see a dentist under the NHS. Sadly, it's the inevitable result of a failed system, where officials bank on dentists missing their targets just so they can plug holes in other budgets.

'Wales has secured major breakthroughs investing in prevention among children, with health inequalities narrowed and a chance to shave millions off treatment costs. What's missing is the willingness to apply that logic to fixing the rotten system at the heart of this service.

'Any progress hinges on the Welsh Government honouring its pledges and delivering real reform. We need a model that puts patient care ahead of tick boxes and targets, that can guarantee access for all who need it.'

A Welsh Government Spokesperson said: 'It is disappointing BDA Wales fail to recognise the significant changes we are making as part of our on-going dental contract reform programme, that are being welcomed by dental clinicians, and which BDA Wales are also actively playing a part in.

'It is important to note access to dental services fluctuates, being dependent on the capacity of individual practices and contractual commitments, which can and does change on a regular basis. We want to see further progress towards a position where everyone in Wales who wants access to NHS dental care can get it.'

1. NHS Direct Wales. Local services search. https://www. nhsdirect.wales.nhs.uk/localservices/Default.aspx (accessed 1 October 2018).

2. Welsh Government. Designed to Smile programme. Available at https://www.designedtosmile.org/welcome-croeso/ welcome/. (accessed 1 October 2018). 